\title{
What should an ideal spinal injury classification system consist of? A methodological review and conceptual proposal for future classifications
}

\author{
Joost J. van Middendorp • Laurent Audigé • \\ Beate Hanson - Jens R. Chapman • \\ Allard J. F. Hosman
}

Received: 18 December 2009/ Accepted: 17 April 2010/Published online: 13 May 2010

(C) The Author(s) 2010. This article is published with open access at Springerlink.com

\begin{abstract}
Since Böhler published the first categorization of spinal injuries based on plain radiographic examinations in 1929, numerous classifications have been proposed. Despite all these efforts, however, only a few have been tested for reliability and validity. This methodological, conceptual review summarizes that a spinal injury classification system should be clinically relevant, reliable and accurate. The clinical relevance of a classification is directly related to its content validity. The ideal content of a spinal injury classification should only include injury characteristics of the vertebral column, is primarily based on the increasingly routinely performed CT imaging, and is clearly distinctive from severity scales and treatment algorithms. Clearly defined observation and conversion criteria are crucial determinants of classification systems'
\end{abstract}

J. J. van Middendorp ( $\square)$ · A. J. F. Hosman

Spine Unit, Department of Orthopaedics,

Radboud University Nijmegen Medical Center,

P.O. Box 9101, 6500 HB Nijmegen, The Netherlands

e-mail: jvanmiddendorp@gmail.com

A. J. F. Hosman

e-mail: a.hosman@orthop.umcn.nl

J. J. van Middendorp · L. Audigé · B. Hanson

AO Clinical Investigation and Documentation,

Dübendorf, Switzerland

e-mail: laurent.audige@aofoundation.org

B. Hanson

e-mail: beate.hanson@aofoundation.org

J. R. Chapman

Department of Orthopaedics, Harborview Medical Center,

University of Washington, Seattle, WA, USA

e-mail: jenschap@u.washington.edu reliability and accuracy. Ideally, two principle spinal injury characteristics should be easy to discern on diagnostic images: the specific location and morphology of the injured spinal structure. Given the current evidence and diagnostic imaging technology, descriptions of the mechanisms of injury and ligamentous injury should not be included in a spinal injury classification. The presence of concomitant neurologic deficits can be integrated in a spinal injury severity scale, which in turn can be considered in a spinal injury treatment algorithm. Ideally, a validation pathway of a spinal injury classification system should be completed prior to its clinical and scientific implementation. This review provides a methodological concept which might be considered prior to the synthesis of new or modified spinal injury classifications.

Keywords Spinal injury · Classification system .

Severity measure $\cdot$ Treatment algorithm .

Methodological review

\section{Introduction}

Prior to the discovery of X-rays by Wilhelm Röntgen in 1895 , the diagnosis of spinal injury was primarily based on clinical observations. Because of the impressive clinical presentation in spinal injury patients with concomitant neurological deficits, spinal injuries were frequently categorized as injuries with or without spinal cord injury (SCI) [19]. Böhler [14] published the first categorization of spinal injuries in 1929 based on plain radiographic examinations of treated spinal injury patients during World War I. Since then, there has been an enormous growth of injury classification systems in spinal trauma literature, ranging from general spinal injury classifications [47, 71], to specific 
classifications of lateral mass injuries of the subaxial cervical spine [59, 63].

Out of the numerous spinal injury classification systems, only a few have been evaluated for reliability or validity [22]. Recently, the Spine Trauma Study Group (STSG) introduced multidimensional injury classification systems for the subaxial cervical and thoracolumbar spine. These classification systems have been evaluated for content validity and subjected to reliability testing by the STSG expert committee [74, 99, 101, 102]. However, the generalizability and practicability of these classifications outside of the expert committee have not been reported to date.

The introduction, evaluation, validation, and clinical and/or scientific implementation of a new classification system is a challenging and time-consuming process [7]. Currently, however, no review evaluating the elementary basics of a spinal injury classification system has been published. The aim of this study is threefold: first, to review the methodological principles of spinal injury classifications; second, to critically appraise the contents of current spinal injury classifications; and third, to discuss future directions of spinal injury classifications.

\section{The principles of spinal injury classification systems}

A spinal injury classification system should be clinically relevant, reliable, and accurate. A classification can only be labeled as 'valid' once it has been proven to fulfill these three crucial criteria. The properties of these three criteria will be reviewed in detail in the following paragraphs.

\section{Clinical relevance of spinal injury classification systems}

\section{Clinical relevance}

Spinal injury classification systems are used as a prognostic tool to determine natural history outcomes, guide treatment decision-making, and predict the possibility of complications [35, 68]. In clinical research, spinal injury classifications are also used to compare different treatments for identical injury types and similar treatments for different injury types [104, 105]. Classification categories that perfectly guide treatment decision-making have excellent construct validity. Construct validity refers to how well a measurement conforms to theoretical constructs. For instance, if a single morphological injury characteristic is theoretically believed to guide between two treatment options, a measure of this characteristic that has construct validity would show this guidance on the choice of treatment [51, 108].

\section{Content and face validity}

A spinal injury classification is considered clinically relevant if it comprises the most relevant items. The content of the classification should be valid. Content validity examines how well the classification represents all aspects of the phenomena under study. Content validity of a classification system is often established through subjective judgments, i.e., face validity, about whether the relevance and applicability of a diagnostic item seems reasonable [51]. To illustrate, the synthesis of the STSG subaxial cervical and thoracolumbar spine injury classification systems were both preceded by extensive review of the literature and consensus achieved at expert meetings [99, 101].

The contents of published spinal injury classifications vary considerably. Both incomprehensive classifications solely based on locations of a fracture line, like the Anderson and D'Alonzo [4] odontoid process fracture classification, and comprehensive classifications based on neurologic function grade, spinal canal deformity, and spinal biomechanical stability, like the Tsou et al. [97] thoracic and lumbar spine injury severity classification, have been introduced. In a review of thoracic and lumbar fracture classifications, Mirza et al. [73] summarized the expectations of an ideal spinal injury classification system. These expectations include descriptions of injury severity, pathogenesis, and causal biomechanical forces, in addition to clinical, neurological, and radiographical characteristics of the injury, see Table 1.

\section{Critical appraisal of the contents of spinal injury classifications}

It is clear that creating an 'ideal' spinal injury classification which includes elements like the ones proposed by Mirza et al. [73] remains an unachievable objective. There are currently no guidelines which specify the minimally required contents of a spinal injury classification. However, in line with the underlying philosophy of the Müller AO Classification of Fractures in Long Bones [75], we believe that the characterization and categorization of spinal injuries should primarily be based on characteristics that can be reliably identified on diagnostic images. The following three key issues clearly illustrate that the content of a spinal injury classification system does not need to be comprehensive at all:

Defining spinal injury: clear semantics, clear focus

The spine (syn.: vertebral column) is defined as "the series of vertebrae that extend from the cranium to the coccyx, 
Table 1 The range of reported expectations for an ideal spinal injury classification system as proposed by Mirza et al. [73], reprinted with permission

\author{
Identification and terminology \\ Allows identification of any injury \\ Is comprehensive and all-inclusive \\ Has a unique value for each discriminatory categorization \\ Offers concise terminology \\ Has descriptive terminology \\ Injury and treatment \\ Describes pathogenesis of the fracture (biologic basis) \\ Reflects the mechanism of injury (biomechanical forces) \\ Contains information regarding severity of injury \\ Guides choice of treatment \\ Characteristics \\ Has easily recognizable clinical characteristics \\ Has easily recognizable radiographic characteristics \\ Has distinguishing clinical characteristics \\ Has distinguishing pathologic characteristics \\ Neurologic factors \\ Describes pattern of neurologic injury \\ Distinguishes etiology of neurologic injury \\ Grades severity of neurologic injury \\ Grading \\ Grades severity of ligamentous injury \\ Grades severity of osseous injury \\ Incorporates fracture anatomy characteristics ${ }^{a}$ \\ Prognostic factors \\ Predicts treatment end results \\ Predicts risk of deformity \\ Predicts risk of additional neurologic injury \\ Predicts natural history \\ Provides tools for future studies
}

${ }^{a}$ Fracture pattern is frequently the dominant or only factor forming the basis of spinal injury classification

providing support and forming a flexible bony case for the spinal cord [93]." Although this definition appears straightforward a clear distinction must be made, for the spinal cord itself is not part of the spine. The spine is a multisegmental osseous structure that covers the spinal cord. Given this definition, spinal trauma can, by definition, result in two closely related yet clearly distinguishable injuries: spinal injury and spinal cord injury (SCI).

Therefore, the content of a spinal injury classification should only include injury characteristics of the vertebral column. Distinguishing spinal injury patients with SCI from spinal injury patients without SCI is rather based on a categorization of the clinical presentation than a classification of the spinal injury itself [19]. Similar to the way soft tissue injuries are classified separately to fractures of long bones
[83], spinal cord injuries should also be classified separately to spinal injuries [18]. Continuing with this parallel, just as the Gustilo-Anderson [41] classification is commonly used to categorize the severity of soft tissue injury, the American Spinal Injury Association (ASIA) International Standards for Neurological Classification of Spinal Cord Injury have become the standardized and routinely adopted classification for traumatic SCI $[1,94]$.

Diagnostic work-up of spinal injuries: principle determinant of classification accuracy

A dramatic shift in the diagnostic work-up of spinal injuries has occurred over the past several years. In contrast to a decade ago, computed tomography (CT) scans of the spine are now being routinely performed during the diagnostic work-up in approximately $80 \%$ of level I trauma centers $[40,96]$. Not without reason. Increasing evidence supports the use of (multi-detector) $\mathrm{CT}$ of the spine rather than conventional radiography in the diagnostic work-up of patients at both high risk and low risk of spinal injuries $[9,17,27,34,39,45,48,70]$. Moreover, with respect to clearance of the spine, magnetic resonance imaging (MRI) of the spine is currently not indicated in the absence of CT abnormalities and neurological deficits [23, 46, 50, 60, 86]. CT images have shown to be more accurate in the visualization of potentially prognostic spinal injury characteristics than conventional radiographs [8, 11, 20, 24, 55, 69] and MRI [49, 57]. In addition, physicians may come to different treatment decisions after examining additional CT images [24, 54].

Given this brief summary of recent advances in the diagnostic work-up of spinal injuries, it is clear that the contents of a contemporary spinal injury classification should primarily be based on the increasingly routinely performed CT imaging.

Classifications, severity measures, and treatment algorithms

Following on from the first two issues, our proposed concept of a spinal injury classification is an incomprehensive one. It should be based on characteristics identified on diagnostic images of the vertebral column only. This concept, however, does not include all prognostic factors associated with spinal injury treatment outcomes. Therefore, other instruments that facilitate case management, communication, and education in the diagnostic-therapeutic pathway of spinal injury can be used in addition to the initial classification (see Fig. 1).

Once a spinal injury has been categorized, the true extent of the injury's severity needs to be evaluated. During this process, other relevant injury classifications, like 


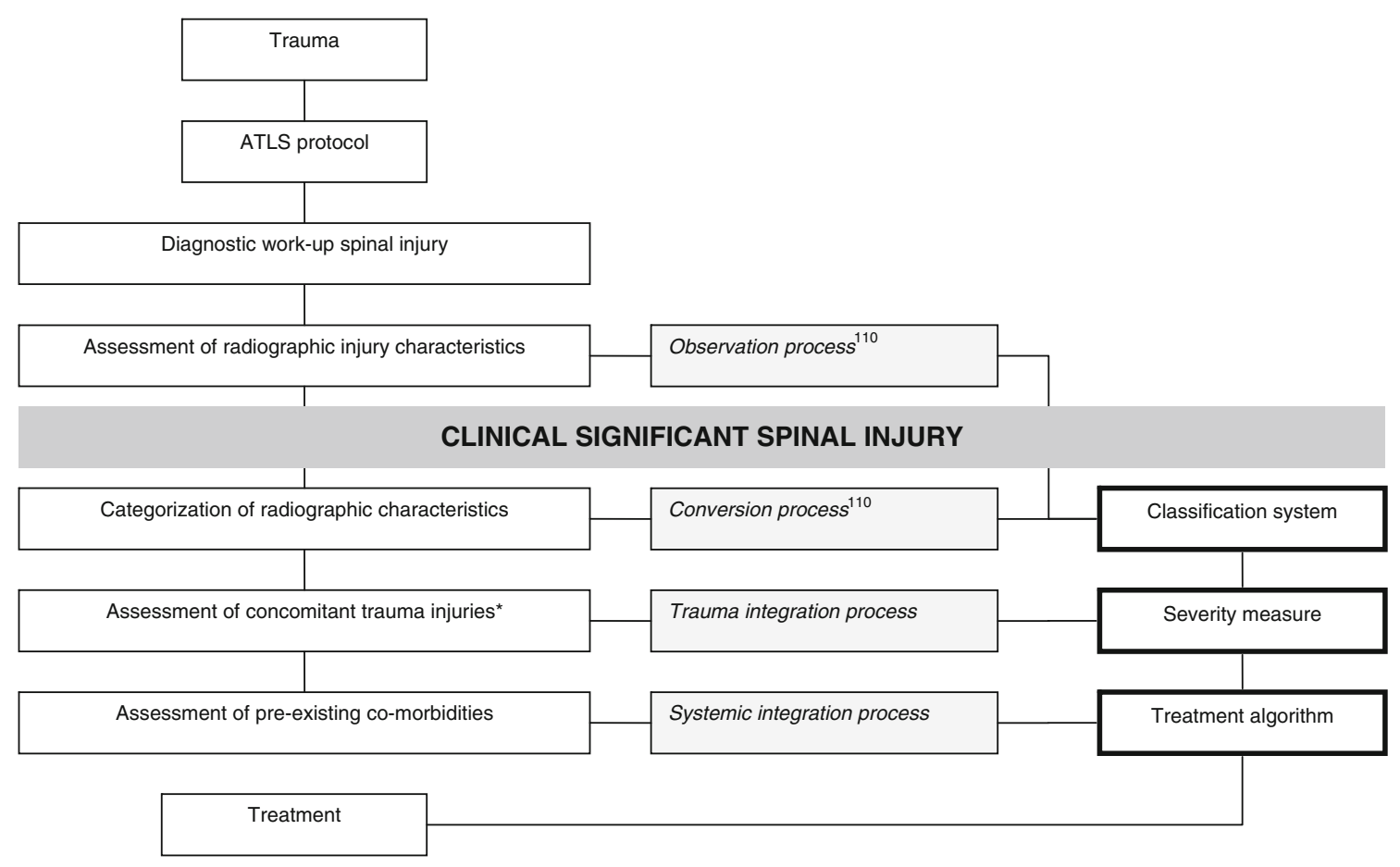

Fig. 1 Flowchart including three instruments in spinal injury management: classifications systems, severity measures, and treatment algorithms. *Including spinal cord injury, ATLS advanced trauma life support

the ASIA International Standards for Classification of Spinal Cord Injury [1], can be integrated into a spinal injury severity measure to direct treatment and determine prognosis. Although controversy remains regarding its effectiveness, surgical spinal decompression is increasingly regarded as indicated in presence of concomitant neurologic deficits [30]. Once the effectiveness of surgical spinal decompression becomes clearer, a spinal injury severity measure or scale can be adapted without altering the underlying spinal injury classification system [81]. In addition to the presence of concomitant neurologic deficits, vascular injuries or even more general injury severity measures can also be considered for integration into a spinal injury severity measure $[10,29]$.

Even more so than a classification system, a severity measure should guide treatment decision making. However, spinal injury treatment decisions are not entirely based on injury severity measures. Pre-existing comorbidities have already shown to be significant prognostic factors of mortality outcomes in the general blunt trauma population [12, 72, 103]. Together with the spinal injury severity measure, these systemic aspects should be integrated into a spinal injury treatment algorithm. In addition, special attention should be given to potential prognostic issues of various treatment options, including the risk of complications. Compared with the other two instruments, the treatment algorithm is potentially most often subjected to adaptations as a result of the steady evolution of treatment options and increasing evidence of their efficacies.

The three spinal injury management instruments are characterized by their increasing grades of clinical relevance. The initial classification systems currently receive the most scientific attention in clinical research. Although potentially useful for clinical decision making, the recently published STSG spinal injury severity measure scales are considered to be of limited value due to a lack of descriptive and communicative dimensions [21]. Even though the STSG subaxial cervical and thoracolumbar spine injury severity scales may have shown excellent evidence of construct validity, the successful scientific implementation of the underlying classification systems remains to be seen $[99,101]$.

\section{Epidemiological properties of spinal injury classification systems}

\section{Reliability}

Reliability, or precision, is the extent to which repeated measurements under similar conditions of the same case agree with one other [25]. In general, there are three potential sources of variation during the classification 
process. These are (1) the patient, (2) the diagnostic instrument, and (3) the physician [110]. As spinal injury classification systems are primarily based on diagnostic imaging, the potential variability of the immobilized, supine patient and diagnostic instrument are normally minimal. If diagnostic images do appear to be of suboptimal quality, new images should be obtained for the sake of patient safety before being evaluated by a physician [80]. Physician variability is the most susceptible factor affecting the reliability of the classification.

Two types of physician, or observer, variation are commonly distinguished in fracture classifications: interrater reliability and intra-rater reliability. Inter-rater reliability assesses the reliability, or agreement, of the classification system when measured by different people under similar conditions. Intra-rater reliability assesses the reliability, or reproducibility, of the classification system when measured more than once by the same rater. From a clinical perspective, the inter-rater reliability of a classification system is considered to be more important than the intra-rater reliability.

\section{Accuracy}

Accuracy is the degree to which the classification system actually represents what it is intended to represent. The accuracy of a measurement is best assessed by comparing it whenever possible to a 'reference standard' technique that is considered to accurately represent the truth. Although no studies correlating CT detected fracture and dislocation patterns with intraoperative findings have been published so far, CT is currently regarded as the number one reference standard with very high sensitivity rates being reported $[9,17,27,34,39,45,48,70]$.

\section{Reliability, accuracy, and error}

The principle difference between reliability and accuracy is that reliability concerns reproducibility and agreement, whereas accuracy concerns representativeness of reality. An unreliable classification system is unlikely to be accurate because of its inherent variability. A classification system can be shown to be reliable, yet it may not be accurate. For instance, Bach et al. [8] reported higher inter-observer agreement in the detection of cervical spine fractures with plain radiographs than with CT images. Nevertheless, CT was more sensitive in detecting cervical spine fractures than plain radiography [8].

Although a clear distinction between these types of error exists, many of the strategies to increase reliability will also improve accuracy [51].

\section{Factors that influence the reliability of spinal injury classification systems}

\section{Observation and conversion processes}

As previously mentioned, it is physician or observer variability that is most likely to affect a fracture classification's reliability. Wright and Feinstein identified two physicianrelated components during the classification process: the first step is the observation process and the second step is the conversion process (see Fig. 1) [110]. During the observation process the physician assesses the extent of the injury by discerning available diagnostic images, ideally with use of predefined process criteria.

The STSG has published three valuable review articles on diagnostic imaging measurement techniques for spinal injuries $[15,16,56]$. They concluded that most of the currently available measurement techniques have not been tested for reliability, accuracy, and validity. Nonetheless, the standardization of observational process criteria may considerably improve observer reliability [110].

Once the properties of the spinal injury have been determined on diagnostic images, the second phase starts: the conversion process. The criteria used to categorize observational data are called conversion criteria [110]. These conversion criteria are literarily the most crucial ones that can make or break the reliability of a spinal injury classification system. The ideal properties of spinal injury classification conversion criteria, or categories, are shown in Table 2 and are summarized below.

\section{Ideal properties of spinal injury classification categories}

1. Clear definitions without ambiguity or freedom of interpretation. If a category description includes subjective terms like minimal, intermediate, or severe dislocation, observers will interpret the severity of a dislocation based on their individual experience [67]. An ideal classification system should result in minimal variability between experienced and inexperienced

Table 2 Ideal properties of spinal injury classification categories

1. Clear definitions without ambiguity or freedom of interpretation

2. All-inclusive and mutually exclusive

3. Clearly distinguishable representative graphic illustrations

4. Straightforward and practicable for daily use

5. Limited number of categories

6. Characterized by increasing grades of severity

7. Each (sub)category alphanumerically coded

8. Injury characteristics easily discernable on diagnostic images 
observers. In order to increase reproducibility and agreement, explanation and elaboration documents can be formulated [1].

2. All-inclusive and mutually exclusive. A classification system should ideally cover all injuries of clinically relevant structures. What clinically relevant structures actually are is a matter of content validity, as previously outlined. Spinal injury patterns should fit into one category only. Once proven to be reliable and valid, quantifiable (measurement) criteria can be applied as an effective categorization tool [110].

3. Clearly distinguishable representative graphic illustrations. Since fracture classifications are primarily based on diagnostic images, graphic illustrations have proven to be an effective means of simplification and clarification [75]. Chapman and colleagues [22] published a valuable reference work providing detailed illustrations of each category in spinal injury classifications available to date.

4. Straightforward and practicable for daily use. A classification system should ideally not consist of a variety of parameters with each parameter requiring different, comprehensive or cost-ineffective diagnostic interventions. In addition, each injury category should preferably be summarized in a single phrase.

5. Limited number of categories. In the search for the ideal classification system, there has always been tension between the multitude of possible patterns of spinal injury, reduction of information, and clinical relevance. The number of categories reported in thoracolumbar spine injury classifications varies from 6 [69] to 55 [66]. Blauth and colleagues showed that the reliability of the Magerl-AO-classification system decreased by an increasing number of subcategories $[13,66]$. For a clear hierarchical understanding, subcategories should ideally comprise more detailed injury characteristics than main categories.

6. Characterized by increasing grades of severity. The clinical utility of a spinal injury classification improves when categories are arranged in increasing severity. These may indicate the need for a more demanding therapy, a poorer prognosis, or an increased risk of complications.

7. Each (sub)category alphanumerically coded. The application of an alphanumeric coding classification system is the ultimate method of condensing information on injury characteristics [75]. The strength of an alphanumeric coding system is that it utilizes physicians' visualization of injury categories based on only a few characters.

8. Injury characteristics easily discernable on diagnostic images. To discern an injury literally means "to distinguish between physiological and posttraumatic findings with the eyes". The phase of discerning, or detecting, spinal injuries on diagnostic images corresponds to the observation process as described by Wright and Feinstein [110]. Two types of injury characteristics have commonly been used in spinal injury classifications: morphological and biomechanical spinal injury characteristics.

\section{Critical appraisal of current spinal injury characteristic concepts}

Morphologic injury characteristics: a study of structure or form

Because of the central role of diagnostic imaging in the diagnosis of spinal injury, descriptions of morphological characteristics have been reported most often in spinal injury classifications. Morphology literally means "a study of structure or form". In contemporary literature, spinal structures are commonly subcategorized into osseous and disco-ligamentous structures [99, 101].

Böhler [14] was the first to categorize thoracolumbar spinal injuries morphologically based on plain radiographic examinations. Spinal injuries were classified into two main categories: fractures of the vertebral body and fractures of the neural arch. These two morphological anatomical categories were in turn both subcategorized as with or without paralysis.

In 1949, Nicoll [76] applied a more detailed morphological approach to categorize thoracolumbar injuries. Fractures were classified into four main types: (1) anterior wedge fractures, (2) lateral wedge fractures, (3) fracturedislocations, and (4) isolated fractures of the neural arch. These morphological characteristics can be distinguished by discerning vertebral body contours, displacement and/or fracture lines on radiographic (or other diagnostic) images without necessarily interpreting them. Interestingly, Nicoll's four categories were further classified as stable or unstable on the basis of the risk of increased deformity and possible cord injury during functional activities. This means that the secondary ('severity') categorization was based on the initial classification of observational data. Unfortunately, Sir Frank Holdsworth, who is recognized as one of the fathers of spinal trauma, continued Nicoll's posttraumatic spinal stability concept without considering the underlying morphological principles of spinal injuries in 1963 [47].

Two decades later, Aebi and Nazarian [2] reintroduced a comprehensive morphological anatomically based classification of cervical spine injuries. It was concluded that mechanism of injury-based classifications lack clinical relevance because of the limited relationship between 
biomechanical causes of, and treatment options in, spinal injuries. Nevertheless, probably due to its complexity, the Aebi and Nazarian classification did not gain worldwide acceptance $[2,13]$.

While the first morphological descriptions of spinal injuries were mainly focused on the integrity and alignment of osseous structures, the evaluation of the disco-ligamentous integrity gained increasing interest after the introduction of the MRI technology. It was during the 1990s that the use of MRI in detecting ligamentous spinal injury received much scientific attention and showed promising results for future clinical implementation [28, $78,79,85,95]$. More recently, however, conflicting evidence concerning its reliability [37, 42, 87] and accuracy $[62,84,92,107]$ has been published. As suggested in previous reports $[28,62,64,78]$, the true additional value of MRI in the treatment decision-making of spinal injury patients without concomitant neurological deficits has not yet been proven [23]. Because of these current controversies, we do not recommend the use of disco-ligamentous characteristics in spinal injury classifications.

As diagnostic imaging technology continuously evolves and treatment options steadily increase, established and implemented spinal injury classifications may become outdated over time. Classification modifications will then be necessary, similar to re-testing for reliability and validity prior to its clinical and scientific implementation [7].

Biomechanical spinal injury characteristics: speculative causal interpretations

In 1939, Watson-Jones [106] was the first to categorize thoracolumbar vertebral body and facet joint injuries in a biomechanical, morphological manner. Although the three main fracture type categories consisted of morphological descriptions (which are, (1) simple wedge fracture, (2) comminuted fracture, and (3) fracture-dislocation) all three types were considered to be flexion compression fractures of the vertebral body.

Mainly inspired by Watson-Jones's and Holdsworth's initial concepts, the spinal injury classifications introduced during the second half of the twentieth century can be characterized by their predominantly hypothetical biomechanical causal descriptions [3, 26, 31, 36, 43, 109]. Spinal injury descriptions which depend on the physicians' interpretation are still in use [53,65, 100].

In 2005, the STSG introduced the thoracolumbar injury severity scale (TLISS) [102]. This scale is based on the three major injury characteristics: (1) the mechanism of injury, (2) the integrity of the posterior ligamentous complex, and (3) the patient's neurological status. Despite the excellent construct validity of the TLISS as a whole, the interobserver agreement for the injury mechanism was marginal with $\kappa$-values up to 0.33 being reported [44, 82, 98]. These disappointing values were the main reason to justify the introduction of a modification to the TLISS, the Thoracolumbar Injury Classification and Severity Score (TLICS) [101]. In the TLICS, the mechanism of injury has been replaced by a description of morphological injury characteristics as seen on the injury's radiographic images.

In a study evaluating the reliability and validity of both the TLISS as well as the TLICS, Whang et al. found much higher agreement for the TLISS injury mechanism and almost equally high agreement for the TLICS injury morphology category, with $\kappa$-values of 0.636 and 0.626 , respectively. Interestingly, based on these data and the significantly stronger construct validity, the authors suggested that the mechanism of trauma may be a more valuable parameter than fracture morphology for the classification and treatment of thoracolumbar injuries [108].

We do not share this point of view. Although the STSG did modify the TLISS mechanism of injury category into the TLICS morphological characteristics category, the subcategories and textual descriptions are almost similar. It is, in fact, this slight (and incorrect) semantic change which can be considered the main reason for the minimal differences in agreement as presented by Whang et al. [108].

To our knowledge, no mechanistic-based spinal injury classification with clear, unambiguous definitions and mutually exclusive categories exists. Several cadaveric studies have confirmed the difficulties in the reciprocal interpretation of causal biomechanical forces leading to spinal injury. Shono et al. [89] showed that identical vectors and magnitudes of forces applied on the skull resulted in different types of fractures and/or dislocations. Moreover, once the integrity of the spinal column is disrupted at the initial moment of injury, altered injury vectors during subsequent moments of the injury make the interpretation of mechanical forces leading to contiguous or non-contiguous injuries difficult, if not impossible, to interpret [77]. Because of its proven highly speculative nature, we do not recommend the use of biomechanical characteristics in spinal injury classifications [88].

\section{Two crucial spinal injury characteristics: location and morphology}

As shown in Table 3, two principle characteristics should ideally be detectable without difficulty on diagnostic images: the location of spinal injury and the morphology of the injured spinal structure. The location of the spinal injury can be categorized in one of five levels of accuracy: (1) a non-specified location of the spinal injury, (2) injury of a 
spinal region, (3) injury of a spinal (articulating) level, (4) injury of an anatomical structure, and (5) injury of a region within an anatomic structure (see Table 3).

Morphological characteristics should also be easy to discern from diagnostic images. In essence, three major morphological characteristics can be identified: (1) the configuration of the fracture line, (2) the extent of tissue involvement (osseous or disco-ligamentous), and (3) presence of displacement (see Table 3). These three morphological characteristics are crucial aspects in determining the spinal injury's severity and stability. As the estimation of posttraumatic spinal stability is primarily based on the consideration and interpretation of the discerned morphological characteristics, we think that a stability concept should not be integrated in the initial spinal injury classification, but rather in a spinal injury severity measure. Nonetheless, injuries should ideally be characterized by increasing grades of severity in the initial spinal injury classification system. Prior to the implementation of morphological characteristics in a classification system, diagnostic imaging measurements necessary to quantify these characteristics should ideally have been tested for reliability, accuracy, and validity $[15,16,56]$.

The classification of lower cervical spine injuries (CSISS) as recently developed by Anderson perfectly addresses these two principle injury characteristics $[5,74]$. Using only the spinal injury's location and true morphological descriptions, excellent agreement ( $\kappa$-value: 0.883 ) and reproducibility ( $\kappa$-value: 0.977 ) can be obtained. Zehnder et al. [111] confirmed these findings in an external validation study. One should keep in mind, however, that an excellent reproducibility of a classification system does not say anything about its content and construct validity, nor about its clinical utility. For a classification to be clinically relevant and scientifically valid a validation pathway should ideally be completed successfully.

Table 3 Two injury characteristics easily discerned by diagnostic imaging: location and morphology

\begin{tabular}{|c|c|c|c|c|}
\hline Characteristic & Item & Possible descriptives & Example & Reference \\
\hline \multirow[t]{5}{*}{ Location } & Non-specified location & Anatomical & ...A fracture of the spine... & - \\
\hline & Region(s) & Anatomical & ...A fracture of the upper cervical spine... & - \\
\hline & Level(s) & Anatomical & ...A fracture of the axis... & - \\
\hline & $\begin{array}{l}\text { Affected anatomical } \\
\text { structure(s) }\end{array}$ & Anatomical & ....A fracture of the odontoid process of the axis... & - \\
\hline & $\begin{array}{l}\text { Affected region(s) within } \\
\text { anatomic structure(s) }\end{array}$ & Anatomical & $\begin{array}{l}\text {...A fracture of the apical tip of the odontoid } \\
\text { process... }\end{array}$ & [4] \\
\hline \multirow[t]{12}{*}{ Morphology } & $\begin{array}{l}\text { Configuration of fracture } \\
\text { line(s) }\end{array}$ & $\begin{array}{l}\text { Three planes }{ }^{\mathrm{a}} \text {, three axes }{ }^{\mathrm{b}} \text {, } \\
\text { oblique, comminuted }\end{array}$ & $\begin{array}{l}\text {...Anterior superior to posterior inferior fracture } \\
\text { line of the odontoid process... }\end{array}$ & {$[38]$} \\
\hline & Extent of tissue involvement & $\mathrm{mm}$, ratio & ...Superior incomplete burst fracture... & {$[66]$} \\
\hline & Number of tissue parts & $\mathrm{n}$, comminuted & ...There could be two or more fragments... & {$[61]$} \\
\hline & Size of tissue part(s) & $\mathrm{mm}$, ratio & ...A bony fragment larger than $3 \mathrm{~mm} .$. & {$[58]$} \\
\hline & Size of anatomical structure & $\mathrm{mm}(\mathrm{H}, \mathrm{W}, \mathrm{L})$, ratio & $\begin{array}{l}\text {.. The distance between the anterosuperior and } \\
\text { anteroinferior corners... }\end{array}$ & {$[52]$} \\
\hline & \multicolumn{4}{|l|}{ Displacement } \\
\hline & Angulation, (3 planes $)^{\mathrm{a}}$ & degrees, ratio, landmark & ...Angulation $>11^{\circ} \ldots$ & [33] \\
\hline & Rotation, $(3 \text { planes })^{\mathrm{a}}$ & degrees, ratio, landmark & ...Atlanto-axial rotatory subluxation... & {$[32]$} \\
\hline & Dislocation, $(3 \text { planes })^{\mathrm{a}}$ & $\mathrm{mm}$, ratio, landmark & ...Unilateral facet dislocation... & {$[6]$} \\
\hline & Subluxation & $\mathrm{mm}$, ratio, landmark & $\begin{array}{l}\text {..With unilateral subluxation of the articular } \\
\text { procesesus... }\end{array}$ & {$[2]$} \\
\hline & Luxation & $\mathrm{mm}$, ratio, landmark & $\begin{array}{l}\text {... Complete luxation fracture with fracture of the } \\
\text { posterior elements... }\end{array}$ & {$[2]$} \\
\hline & Separation & $\mathrm{mm}$, ratio, landmark & $\begin{array}{l}\text {...Separation of the lateral masses }>7 \mathrm{~mm} \\
\text { laterally... }\end{array}$ & {$[2]$} \\
\hline
\end{tabular}

\footnotetext{
a The three planes are: transverse, sagital, and coronal plane

b The three axes are medial-lateral (X), inferior-superior (Y), and anterior-posterior (Z)

c To date, this radiographic measurement has not been applied in a classification system

$m m$ millimeters, $n$ number, $H$ height, $W$ width, $L$ length
} 


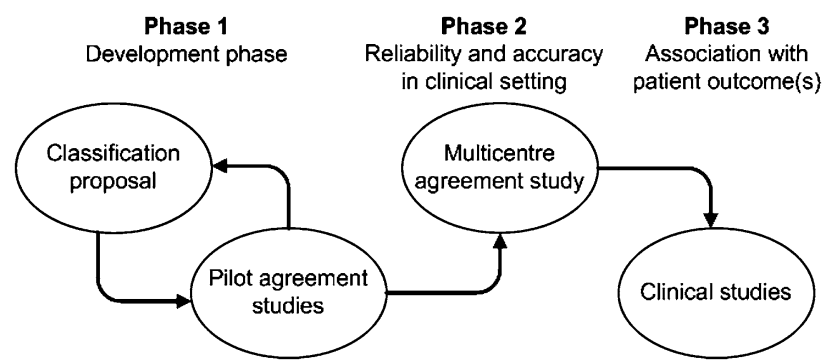

Fig. 2 Three-phase validation process for fracture classification systems as proposed by Audigé et al. [7], reprinted with permission

\section{Validation pathway of spinal injury classification systems}

As the aim of this study was to review methodological aspects faced during the development phase of a spinal injury classification system, the process of validation and clinical implementation has not been described in detail. In 2005, Audigé et al. [7] proposed a 3-phase validation concept for general orthopedic fracture classifications (see Fig. 2). During the first phase, as described in detail in this study, classification categories are defined following extensive literature research and expert consensus meetings. To pursue future success, pilot agreement studies assessing both reliability and accuracy should also be performed during this phase. After the development of a fracture classification, a multicenter agreement study should be conducted among a representative group of future users of the classification. Finally, the prognostic value of the classification needs to be assessed in prospective clinical studies investigating patient outcomes of different treatments.

This methodological pathway has already been shown to result in successful implementation of fracture classification systems, in particular for the development and validation of the AO pediatric long-bone fracture classification system [90, 91]. Currently, the AOSpine Classification Group is developing new spinal injury classification systems using the same validation pathway.

Acknowledgments We are grateful to Prof. F. Magerl for his valuable comments on the manuscript. We also would like to thank Mr. Diarmuid De Faoite for his assistance in the preparation of this manuscript. J.J. van Middendorp was supported by a fellowship from AO Clinical Investigation and Documentation (AOCID).

Open Access This article is distributed under the terms of the Creative Commons Attribution Noncommercial License which permits any noncommercial use, distribution, and reproduction in any medium, provided the original author(s) and source are credited.

\section{References}

1. American Spinal Injury Association: International Standards for Neurological Classification of Spinal Cord Injury, revised 2003. In: American Spinal Injury Association, Chicago, IL
2. Aebi M, Nazarian S (1987) Classification of injuries of the cervical spine. Orthopade 16:27-36

3. Allen BL Jr, Ferguson RL, Lehmann TR, O'Brien RP (1982) A mechanistic classification of closed, indirect fractures and dislocations of the lower cervical spine. Spine 7:1-27

4. Anderson LD, D'Alonzo RT (1974) Fractures of the odontoid process of the axis. J Bone Joint Surg Am 56:1663-1674

5. Anderson PA, Moore TA, Davis KW, Molinari RW, Resnick DK, Vaccaro AR, Bono CM, Dimar JR 2nd, Aarabi B, Leverson G (2007) Cervical spine injury severity score. Assessment of reliability. J Bone Joint Surg Am 89:1057-1065

6. Argenson C, Peretti F, Ghabris A, Eude P, Lovet J, Hovorka I (1997) Classification of lower cervical spine injuries. Eur J Orthop Surg Traumatol 7:215-229

7. Audigé L, Bhandari M, Hanson B, Kellam J (2005) A concept for the validation of fracture classifications. J Orthop Trauma 19:404-409

8. Bach CM, Steingruber IE, Peer S, Peer-Kuhberger R, Jaschke W, Ogon M (2001) Radiographic evaluation of cervical spine trauma. Plain radiography and conventional tomography versus computed tomography. Arch Orthop Trauma Surg 121:385-387

9. Bailitz J, Starr F, Beecroft M, Bankoff J, Roberts R, Bokhari F, Joseph K, Wiley D, Dennis A, Gilkey S, Erickson P, Raksin P, Nagy K (2009) CT should replace three-view radiographs as the initial screening test in patients at high, moderate, and low risk for blunt cervical spine injury: a prospective comparison. J Trauma 66:1605-1609

10. Baker SP, O'Neill B, Haddon W Jr, Long WB (1974) The injury severity score: a method for describing patients with multiple injuries and evaluating emergency care. J Trauma 14:187-196

11. Ballock RT, Mackersie R, Abitbol JJ, Cervilla V, Resnick D, Garfin SR (1992) Can burst fractures be predicted from plain radiographs? J Bone Joint Surg Br 74-B:147-150

12. Bamvita JM, Bergeron E, Lavoie A, Ratte S, Clas D (2007) The impact of premorbid conditions on temporal pattern and location of adult blunt trauma hospital deaths. J Trauma 63:135-141

13. Blauth M, Bastian L, Knop C, Lange U, Tusch G (1999) Interobserver reliability in the classification of thoraco-lumbar spinal injuries. Orthopade 28:662-681

14. Böhler L (1929) The treatment of fractures. A translation of "Technik der Knochenbruchbehandlung im Frieden und im Kriege" by M.E. Steinberg. Wilhelm Maudrich, Vienna, Austria

15. Bono CM, Vaccaro AR, Fehlings M, Fisher C, Dvorak M, Ludwig S, Harrop J (2006) Measurement techniques for lower cervical spine injuries: consensus statement of the Spine Trauma Study Group. Spine (Phila Pa 1976) 31:603-609

16. Bono CM, Vaccaro AR, Fehlings M, Fisher C, Dvorak M, Ludwig S, Harrop J (2007) Measurement techniques for upper cervical spine injuries: consensus statement of the Spine Trauma Study Group. Spine 32:593-600

17. Brown CV, Antevil JL, Sise MJ, Sack DI (2005) Spiral computed tomography for the diagnosis of cervical, thoracic, and lumbar spine fractures: its time has come. J Trauma 58:890-895 (discussion 895-896)

18. Bucholz RW, Gill K (1986) Classification of injuries to the thoracolumbar spine. Orthop Clin N A 17:67-73

19. Burrell HL (1905) I. Fracture of the spine: a summary of all the cases (244) which were treated at the Boston City Hospital from 1864 to 1905 . Ann Surg 42:481-506

20. Campbell SE, Phillips CD, Dubovsky E, Cail WS, Omary RA (1995) The value of CT in determining potential instability of simple wedge-compression fractures of the lumbar spine. AJNR Am J Neuroradiol 16:1385-1392

21. Chapman JR (2009) Classifications in spine: a tectonic shift. Spine J 9:776-777 
22. Chapman JR, Dettori JR, Norvell DC (eds) (2009) Spine Classifications and Severity Measures. Thieme Verlag, New York

23. Dai L-YMDP, Ding W-GMDM, Wang X-YMDP, Jiang LSMDP, Jiang S-DMDP, Xu H-ZMD (2009) Assessment of ligamentous injury in patients with thoracolumbar burst fractures using MRI. J Trauma-Injury Infect Crit Care 66:1610-1615

24. Dai LY, Wang XY, Jiang LS, Jiang SD, Xu HZ (2008) Plain radiography versus computed tomography scans in the diagnosis and management of thoracolumbar burst fractures. Spine (Phila $\mathrm{Pa}$ 1976) 33:E548-E552

25. Daly LE, Bourke GJ (2007) Interpretation and uses of medical statistics. Blackwell, Oxford, UK, pp 381-392

26. Denis F (1983) The three column spine and its significance in the classification of acute thoracolumbar spinal injuries. Spine 8:817-831

27. Diaz JJ Jr, Cullinane DC, Altman DT, Bokhari F, Cheng JS, Como J, Gunter O, Holevar M, Jerome R, Kurek SJ Jr, Lorenzo M, Mejia V, Miglietta M, O’Neill PJ, Rhee P, Sing R, Streib E, Vaslef S (2007) Practice management guidelines for the screening of thoracolumbar spine fracture. J Trauma 63:709-718

28. Emery SE, Pathria MN, Wilber RG, Masaryk T, Bohlman HH (1989) Magnetic resonance imaging of posttraumatic spinal ligament injury. J Spinal Disord 2:229-233

29. Fassett DR, Dailey AT, Vaccaro AR (2008) Vertebral artery injuries associated with cervical spine injuries: a review of the literature. J Spinal Disord Tech 21:252-258

30. Fehlings MG, Perrin RG (2006) The timing of surgical intervention in the treatment of spinal cord injury: a systematic review of recent clinical evidence. Spine 31:S28-S35 (discussion S36)

31. Ferguson RL, Allen BL, Jr (1984) A mechanistic classification of thoracolumbar spine fractures. Clin Orthop Relat Res 189:7788

32. Fielding JW, Hawkins RJ (1977) Atlanto-axial rotatory fixation. (Fixed rotatory subluxation of the atlanto-axial joint). J Bone Joint Surg Am 59:37-44

33. Francis WR, Fielding JW, Hawkins RJ, Pepin J, Hensinger R (1981) Traumatic spondylolisthesis of the axis. J Bone Joint Surg Br 63-B:313-318

34. Gale SC, Gracias VH, Reilly PM, Schwab CW (2005) The inefficiency of plain radiography to evaluate the cervical spine after blunt trauma. J Trauma 59:1121-1125

35. Garbuz DS, Masri BA, Esdaile J, Duncan CP (2002) Classification systems in orthopaedics. J Am Acad Orthop Surg 10:290297

36. Gertzbein SD, Court-Brown CM (1988) Flexion-distraction injuries of the lumbar spine. Mechanisms of injury and classification. Clin Orthop Relat Res 227:52-60

37. Goradia D, Linnau KF, Cohen WA, Mirza S, Hallam DK, Blackmore CC (2007) Correlation of MR imaging findings with intraoperative findings after cervical spine trauma. AJNR Am J Neuroradiol 28:209-215

38. Grauer JN, Shafi B, Hilibrand AS, Harrop JS, Kwon BK, Beiner JM, Albert TJ, Fehlings MG, Vaccaro AR (2005) Proposal of a modified, treatment-oriented classification of odontoid fractures. Spine J 5:123-129

39. Griffen MM, Frykberg ER, Kerwin AJ, Schinco MA, Tepas JJ, Rowe K, Abboud J (2003) Radiographic clearance of blunt cervical spine injury: plain radiograph or computed tomography scan? J Trauma 55:222-226 (discussion 226-227)

40. Grossman MDMD, Reilly PMMD, Gillett TBS, Gillett DBS (1999) National survey of the Incidence of cervical spine injury and approach to cervical spine clearance in U.S. Trauma centers. J Trauma-Injury Infect Crit Care 47:684

41. Gustilo RB, Anderson JT (1976) Prevention of infection in the treatment of one thousand and twenty-five open fractures of long bones: retrospective and prospective analyses. J Bone Joint Surg [Am] 58:453-458

42. Haba H, Taneichi H, Kotani Y, Terae S, Abe S, Yoshikawa H, Abumi K, Minami A, Kaneda K (2003) Diagnostic accuracy of magnetic resonance imaging for detecting posterior ligamentous complex injury associated with thoracic and lumbar fractures. $\mathrm{J}$ Neurosurg 99:20-26

43. Harris JH Jr, Edeiken-Monroe B, Kopaniky DR (1986) A practical classification of acute cervical spine injuries. Orthop Clin North Am 17:15-30

44. Harrop JS, Vaccaro AR, Hurlbert RJ, Wilsey JT, Baron EM, Shaffrey CI, Fisher CG, Dvorak MF, Oner FC, Wood KB, Anand N, Anderson DG, Lim MR, Lee JY, Bono CM, Arnold PM, Rampersaud YR, Fehlings MG (2006) Intrarater and interrater reliability and validity in the assessment of the mechanism of injury and integrity of the posterior ligamentous complex: a novel injury severity scoring system for thoracolumbar injuries. Invited submission from the Joint Section Meeting On Disorders of the Spine and Peripheral Nerves, March 2005. J Neurosurg Spine 4:118-122

45. Hauser CJ, Visvikis G, Hinrichs C, Eber CD, Cho K, Lavery RF, Livingston DH (2003) Prospective validation of computed tomographic screening of the thoracolumbar spine in trauma. $\mathbf{J}$ Trauma 55:228-234 (discussion 234-225)

46. Hogan GJ, Mirvis SE, Shanmuganathan K, Scalea TM (2005) Exclusion of unstable cervical spine injury in obtunded patients with blunt trauma: is MR imaging needed when multi-detector row CT findings are normal?1. Radiology 237:106-113

47. Holdsworth FW (1963) Fractures, dislocations, and fracturedislocations of the spine. J Bone Joint Surg Br 45-B:6-20

48. Holmes JF, Akkinepalli R (2005) Computed tomography versus plain radiography to screen for cervical spine injury: a metaanalysis. J Trauma 58:902-905

49. Holmes JF, Mirvis SE, Panacek EA, Hoffman JR, Mower WR, Velmahos GC (2002) Variability in computed tomography and magnetic resonance imaging in patients with cervical spine injuries. J Trauma 53:524-529 (discussion 530)

50. Horn EM, Theodore N, Feiz-Erfan I, Lekovic GP, Dickman CA, Sonntag VK (2006) Complications of halo fixation in the elderly. J Neurosurg Spine 5:46-49

51. Hulley SB, Cummings SR, Browner WS, Grady DG, Newman TB (eds) (2006) Designing clinical research. Lippincott Williams and Wilkins, Philadelphia, PA, pp 37-49

52. Isomi T, Panjabi MM, Kato Y, Wang JL (2000) Radiographic parameters for evaluating the neurological spaces in experimental thoracolumbar burst fractures. J Spinal Disord 13:404411

53. Joseph SA Jr, Stephen M, Meinhard BP (2008) The successful short-term treatment of flexion-distraction injuries of the thoracic spine using posterior-only pedicle screw instrumentation. J Spinal Disord Tech 21:192-198

54. Katz MA, Beredjiklian PK, Vresilovic EJ, Tahernia AD, Gabriel JP, Chan PS, Heppenstall RB (1999) Computed tomographic scanning of cervical spine fractures: does it influence treatment? J Orthop Trauma 13:338-343

55. Keene JS, Goletz TH, Lilleas F, Alter AJ, Sackett JF (1982) Diagnosis of vertebral fractures. A comparison of conventional radiography, conventional tomography, and computed axial tomography. J Bone Joint Surg Am 64:586-594

56. Keynan O, Fisher CG, Vaccaro A, Fehlings MG, Oner FC, Dietz J, Kwon B, Rampersaud R, Bono C, France J, Dvorak M (2006) Radiographic measurement parameters in thoracolumbar fractures: a systematic review and consensus statement of the spine trauma study group. Spine (Phila Pa 1976) 31:E156-E165

57. Klein GR, Vaccaro AR, Albert TJ, Schweitzer M, Deely D, Karasick D, Cotler JM (1999) Efficacy of magnetic resonance 
imaging in the evaluation of posterior cervical spine fractures. Spine 24:771-774

58. Korres DS, Benetos IS, Evangelopoulos DS, Athanasssacopoulos M, Gratsias P, Papamichos O, Babis GC (2007) Tear-drop fractures of the lower cervical spine: classification and analysis of 54 cases. Eur J Orthop Surg Traumatol 17:521-526

59. Kotani Y, Abumi K, Ito M, Minami A (2005) Cervical spine injuries associated with lateral mass and facet joint fractures: new classification and surgical treatment with pedicle screw fixation. Eur Spine J 14:69-77

60. Labattaglia MP, Cameron PA, Santamaria M, Varma D, Thomson K, Bailey M, Kossmann T (2007) Clinical outcomes of magnetic resonance imaging in blunt cervical trauma. Emerg Med Australas 19:253-261

61. Landells CD, Van Peteghem PK (1988) Fractures of the atlas: classification, treatment and morbidity. Spine 13:450-452

62. Lee HM, Kim HS, Kim DJ, Suk KS, Park JO, Kim NH (2000) Reliability of magnetic resonance imaging in detecting posterior ligament complex injury in thoracolumbar spinal fractures. Spine (Phila Pa 1976) 25:2079-2084

63. Lee SH, Sung JK (2009) Unilateral lateral mass-facet fractures with rotational instability: new classification and a review of 39 cases treated conservatively and with single segment anterior fusion. J Trauma 66:758-767

64. Leferink VJ, Veldhuis EF, Zimmerman KW, ten Vergert EM, ten Duis HJ (2002) Classificational problems in ligamentary distraction type vertebral fractures: $30 \%$ of all B-type fractures are initially unrecognised. Eur Spine J 11:246-250

65. Liu P, Zhao J, Liu F, Liu M, Fan W (2008) A novel operative approach for the treatment of old distractive flexion injuries of subaxial cervical spine. Spine (Phila Pa 1976) 33:1459-1464

66. Magerl F, Aebi M, Gertzbein SD, Harms J, Nazarian S (1994) A comprehensive classification of thoracic and lumbar injuries. Eur Spine J 3:184-201

67. Martin J, Marsh JL, Nepola JV, Dirschl DR, Hurwitz S, DeCoster TA (2000) Radiographic fracture assessments: which ones can we reliably make? J Orthop Trauma 14:379-385

68. Martin JS, Marsh JL (1997) Current classification of fractures. Rationale and utility. Radiol Clin N A 35:491-506

69. McAfee PC, Yuan HA, Fredrickson BE, Lubicky JP (1983) The value of computed tomography in thoracolumbar fractures. An analysis of one hundred consecutive cases and a new classification. J Bone Joint Surg Am 65:461-473

70. McCulloch PT, France J, Jones DL, Krantz W, Nguyen T-P, Chambers C, Dorchak J, Mucha P (2005) Helical computed tomography alone compared with plain radiographs with adjunct computed tomography to evaluate the cervical spine after highenergy trauma. J Bone Joint Surg Am 87:2388-2394

71. Meyer P (2000) Universal spine fracture classification. Chir Organi Mov 85:95-100

72. Milzman DP, Boulanger BR, Rodriguez A, Soderstrom CA, Mitchell KA, Magnant CM (1992) Pre-existing disease in trauma patients: a predictor of fate independent of age and injury severity score. J Trauma 32:236-243 (discussion 243-234)

73. Mirza SK, Mirza AJ, Chapman JR, Anderson PA (2002) Classifications of thoracic and lumbar fractures: rationale and supporting data. J Am Acad Orthop Surg 10:364-377

74. Moore TA, Vaccaro AR, Anderson PA (2006) Classification of lower cervical spine injuries. Spine 31:S37-S43

75. Müller ME, Nazarian S, Koch P (1987) Classification AO des fractures. Tome I. Les os longs. Springer, Berlin

76. Nicoll EA (1949) Fractures of the dorso-lumbar spine. J Bone Joint Surg Br 31-B:376-394

77. Nightingale RW, McElhaney JH, Richardson WJ, Best TM, Myers BS (1996) Experimental impact injury to the cervical spine: relating motion of the head and the mechanism of injury. J Bone Joint Surg Am 78:412-421

78. Oner FC, van Gils APG, Dhert WJA, Verbout AJ (1999) MRI findings of thoracolumbar spine fractures: a categorisation based on MRI examinations of 100 fractures. Skeletal Radiol 28:433443

79. Petersilge CA, Pathria MN, Emery SE, Masaryk TJ (1995) Thoracolumbar burst fractures: evaluation with MR imaging. Radiology 194:49-54

80. Poonnoose PMMS, Ravichandran GF, McClelland MRF (2002) Missed and mismanaged injuries of the spinal cord. J TraumaInjury Infection Crit Care 53:314-320

81. Rahimi-Movaghar V, Saadat S, Vaccaro A, Ghodsi SM, Samadian M, Sheykhmozaffari A, Safdari SM, Keshmirian B (2009) The efficacy of surgical decompression before 24 hours versus 24 to 72 hours in patients with spinal cord injury from T1 to L1 - with specific consideration on ethics: a randomized controlled trial. Trials 10:77

82. Raja Rampersaud Y, Fisher C, Wilsey J, Arnold P, Anand N, Bono CM, Dailey AT, Dvorak M, Fehlings MG, Harrop JS, Oner FC, Vaccaro AR (2006) Agreement between orthopedic surgeons and neurosurgeons regarding a new algorithm for the treatment of thoracolumbar injuries: a multicenter reliability study. J Spinal Disord Tech 19:477-482

83. Rüedi TP, Buckley RE, Moran CG (eds) (2007) AO principles of fracture management, vol 1: principles. Thieme Verlag, New York, NY

84. Saifuddin A, Green R, White J (2003) Magnetic resonance imaging of the cervical ligaments in the absence of trauma. Spine (Phila Pa 1976) 28:1686-1691 (discussion 1691-1682)

85. Saifuddin A, Noordeen H, Taylor BA, Bayley I (1996) The role of imaging in the diagnosis and management of thoracolumbar burst fractures: current concepts and a review of the literature. Skeletal Radiol 25:603-613

86. Schuster R, Waxman K, Sanchez B, Becerra S, Chung R, Conner S, Jones T (2005) Magnetic resonance imaging is not needed to clear cervical spines in blunt trauma patients with normal computed tomographic results and no motor deficits. Arch Surg 140:762-766

87. Schweitzer KM Jr, Vaccaro AR, Harrop JS, Hurlbert J, Carrino JA, Rechtine GR, Schwartz DG, Alanay A, Sharma DK, Anderson DG, Lee JY, Arnold PM (2007) Interrater reliability of identifying indicators of posterior ligamentous complex disruption when plain films are indeterminate in thoracolumbar injuries. J Orthop Sci 12:437-442

88. Schweitzer KM Jr, Vaccaro AR, Lee JY, Grauer JN (2006) Confusion regarding mechanisms of injury in the setting of thoracolumbar spinal trauma: a survey of The Spine Trauma Study Group (STSG). J Spinal Disord Tech 19:528-530

89. Shono Y, McAfee PC, Cunningham BW (1993) The pathomechanics of compression injuries in the cervical spine. Nondestructive and destructive investigative methods. Spine (Phila $\mathrm{Pa}$ 1976) 18:2009-2019

90. Slongo T, Audig L, Schlickewei W, Clavert JM, Hunter J (2006) Development and validation of the AO pediatric comprehensive classification of long bone fractures by the Pediatric Expert Group of the AO Foundation in collaboration with AO Clinical Investigation and Documentation and the International Association for Pediatric Traumatology. J Pediatr Orthop 26:43-49

91. Slongo T, Audige L, Clavert JM, Lutz N, Frick S, Hunter J (2007) The AO comprehensive classification of pediatric longbone fractures: a web-based multicenter agreement study. J Pediatr Orthop 27:171-180

92. Stabler A, Eck J, Penning R, Milz SP, Bartl R, Resnick D, Reiser M (2001) Cervical spine: postmortem assessment of 
accident injuries-comparison of radiographic, MR imaging, anatomic, and pathologic findings. Radiology 221:340-346

93. Stedman's Medical Dictionary (2005) Lippincott Williams and Wilkins. Philadelphia, PA

94. Steeves JD, Lammertse D, Curt A, Fawcett JW, Tuszynski MH, Ditunno JF, Ellaway PH, Fehlings MG, Guest JD, Kleitman N, Bartlett PF, Blight AR, Dietz V, Dobkin BH, Grossman R, Short D, Nakamura M, Coleman WP, Gaviria M, Privat A (2007) Guidelines for the conduct of clinical trials for spinal cord injury (SCI) as developed by the ICCP panel: clinical trial outcome measures. Spinal Cord 45:206-221

95. Terk MR, Hume-Neal M, Fraipont M, Ahmadi J, Colletti PM (1997) Injury of the posterior ligament complex in patients with acute spinal trauma: evaluation by MR imaging. Am J Roentgenol 168:1481-1486

96. Thomas J, Rideau AM, Paulson EK, Bisset Iii GS (2008) Emergency department imaging: current practice. J Am College Radiol 5:e811-2816, e812

97. Tsou PM, Wang J, Khoo L, Shamie AN, Holly L (2006) A thoracic and lumbar spine injury severity classification based on neurologic function grade, spinal canal deformity, and spinal biomechanical stability. Spine J 6:636-647

98. Vaccaro AR, Baron EM, Sanfilippo J, Jacoby S, Steuve J, Grossman E, DiPaola M, Ranier P, Austin L, Ropiak R, Ciminello M, Okafor C, Eichenbaum M, Rapuri V, Smith E, Orozco F, Ugolini P, Fletcher M, Minnich J, Goldberg G, Wilsey J, Lee JY, Lim MR, Burns A, Marino R, DiPaola C, Zeiller L, Zeiler SC, Harrop J, Anderson DG, Albert TJ, Hilibrand AS (2006) Reliability of a novel classification system for thoracolumbar injuries: the thoracolumbar injury severity score. Spine 31:S62S69 (discussion S104)

99. Vaccaro AR, Hulbert RJ, Patel AA, Fisher C, Dvorak M, Lehman RA Jr, Anderson P, Harrop J, Oner FC, Arnold P, Fehlings M, Hedlund R, Madrazo I, Rechtine G, Aarabi B, Shainline M (2007) The subaxial cervical spine injury classification system: a novel approach to recognize the importance of morphology, neurology, and integrity of the disco-ligamentous complex. Spine 32:2365-2374

100. Vaccaro AR, Klein GR, Thaller JB, Rushton SA, Cotler JM, Albert TJ (2001) Distraction extension injuries of the cervical spine. J Spinal Disord 14:193-200
101. Vaccaro AR, Lehman RA Jr, Hurlbert RJ, Anderson PA, Harris M, Hedlund R, Harrop J, Dvorak M, Wood K, Fehlings MG, Fisher C, Zeiller SC, Anderson DG, Bono CM, Stock GH, Brown AK, Kuklo T, Oner FC (2005) A new classification of thoracolumbar injuries: the importance of injury morphology, the integrity of the posterior ligamentous complex, and neurologic status. Spine 30:2325-2333

102. Vaccaro AR, Zeiller SC, Hulbert RJ, Anderson PA, Harris M, Hedlund R, Harrop J, Dvorak M, Wood K, Fehlings MG, Fisher C, Lehman RA Jr, Anderson DG, Bono CM, Kuklo T, Oner FC (2005) The thoracolumbar injury severity score: a proposed treatment algorithm. J Spinal Disord Tech 18(3):209-215

103. van Middendorp JJ, Albert TJ, Veth RPH, Hosman AJF (2010) Methodological systematic review: mortality in elderly patients with cervical spine injury: a critical appraisal of the reporting of baseline characteristics, follow-up, cause of death, and analysis of risk factors. Spine 35:1079-1087

104. Verlaan JJ, Diekerhof CH, Buskens E, van der Tweel I, Verbout AJ, Dhert WJ, Oner FC (2004) Surgical treatment of traumatic fractures of the thoracic and lumbar spine: a systematic review of the literature on techniques, complications, and outcome. Spine 29:803-814

105. Vieweg U, Schultheiss R (2001) A review of halo vest treatment of upper cervical spine injuries. Arch Orthop Trauma Surg 121:50 55

106. Watson-Jones R (1938) The results of postural reduction of fractures of the spine. J Bone Joint Surg Am 20:567-586

107. Weißkopf M, Bail H, Mack M, Stöckle U, Hoffmann R (1999) Wertigkeit der MRT bei traumatischer diskoligamentärer Instabilität der unteren HWS. Der Unfallchirurg 102:942-948

108. Whang PG, Vaccaro AR (2007) Thoracolumbar fracture: posterior instrumentation using distraction and ligamentotaxis reduction. J Am Acad Orthop Surg 15:695-701

109. Whitley JE, Forsyth HF (1960) The classification of cervical spine injuries. Am J Roentgenol Radium Ther Nucl Med 83:633-644

110. Wright JG, Feinstein AR (1992) Improving the reliability of orthopaedic measurements. J Bone Joint Surg Br 74-B:287-291

111. Zehnder SW, Lenarz CJ, Place HM (2009) Teachability and reliability of a new classification system for lower cervical spinal injuries. Spine 34:2039-2043 